\title{
EMOTIONAL INTELLIGENCE - AN ESSENTIAL COMPONENT IN CREATING A MODERN LEADER
}

\author{
Diana Chiș-Manolache ${ }^{1}$ \\ "Carol l" National Defence University
}

\begin{abstract}
This paper presents, in a concise manner, the importance of emotional intelligence in shaping the profile of the modern leader. Compared to the leader of the last century, the modern leader needs a multitude of skills in the field of emotional intelligence in order to deal with the change and to adapt to the realities of the organizational environment. Aspects such as self-awareness, self-regulation, motivation, empathy are just some of the skills that the modern leader must have, so that he can give consistency to the act of leadership. In this context, motivation is also a basic pillar that builds an effective relationship between the leader and his team. A motivated leader may be able to motivate his team and conduct it on the road to success.
\end{abstract}

Keywords: leader; emotional intelligence; leadership; organizations.

\section{INTRODUCTION}

True leaders are authentic and impress in absolutely every situation in which they act. If we were to try to identify the basis of their efficiency, we will discover strategy, vision, creativity. Moreover, true leaders impress because they always appeal to emotions. The way they act determines their own success and implicitly the success of the teams they lead. No matter how many qualities they have and no matter how skilled they are in the field of activity, if they fail to direct their emotions on the right path, they will certainly not be able to do what they set out to do, to the desired standards.

Over time, leaders were the ones who guided their subordinates, the ones who provided clarity and security, in times of uncertainty or when the subordinates had tasks to solve. In the current period, the architecture of organizations has undergone transformations, and the leader has become an emotional guide, responsible for directing the group's emotions in the positive direction and for eliminating harmful emotions. If the team's emotions converge towards enthusiasm, its members give performance and reach performance standards, while if their anxiety is aroused, their performance will decrease and the goal will not be achieved.

The main pillar in leadership based on emotional intelligence is the leader's use of skills in the field of emotional intelligence, very important in this context being how the leader relates to himself, but also how he relates to his team members. The important tasks of the leader are, on the one hand, to achieve within the team, a comfortable atmosphere, based on trust, and on the other hand to instill enthusiasm and passion in solving all projects. These responsibilities can be easily fulfilled by the leader if he has specific skills of emotional intelligence, such as self-knowledge, social awareness, self-control, relationship management.

\section{METHODOLOGY}

The paper is the result of an empirical documentary analysis conducted by studying and analyzing works that address the importance of emotional intelligence in the context of modern leadership. Given that observation is the first method of data collection used, the paper is mainly based on explanatory research, research with the help of which we highlighted the emotional skills that underlie the profile of an efficient leader.

\footnotetext{
${ }^{1}$ Corresponding author: dianachis1488@gmail.com
} 
The approach of some components specific to emotional intelligence, specific to today's leader is the result of an empirical documentary analysis, and the conclusions drawn may be the basis of a new documentary study, much more complex and comprehensive. The empirical research carried out will open new research directions, current, being strongly anchored in the reality of today.

\section{CONSIDERATIONS REGARDING THE CONCEPT OF EMOTIONAL INTELLIGENCE}

The Socratic call "Know thyself!" encapsulates in two words the most essential elements of emotional intelligence, highlighting, in fact, the awareness of one's own feelings in the moment they appear inside each one.

Self-knowledge or metacognition, which refers to the awareness of one's own thought processes and meta-disposition, which refers to the awareness of emotions as psychologists describe them, have held the attention over time of many psychologists and psychoanalysts around the world, as extremely interesting processes. Awareness of one's own inner states, one's own emotions is called by some psychoanalysts as the observant self, i.e., self-awareness that allows the analyst to monitor their own reactions to the patient's words and the process of free association that the patient weaves. (Mark 1995)

In this sense, it is important to mention that in the physiological processes that take place, a neocortex is activated in the lingual area, being responsible for identifying the emotions that have occurred. Therefore, the awareness of one's emotions is in close connection with self-observation, in fact, the internal observation is the one that allows the awareness of emotions.

In other words, self-awareness, the element that underlies emotional intelligence, refers to being aware of both the mood in which the individual is and the position and what he thinks about this mood.

Emotional Intelligence Theory (EQ) is a concept often used in psychology, being brought to attention by John Mayer, a psychologist at the University of New Hampshire and Peter Salovey, of Yale University (1990), the term being later deepened by Daniel Goleman, in 1995, through the work of the same name, a concept applied by him in 1998, in the business domain.

According to the postulate of the psychologist John Mayer, self-awareness is a careful reflection on the inner state. This psychologist also believes that the discontinuity between awareness of one's feelings and taking concrete actions to change them should be overcome. So, practically speaking, when one can recognize the existence of inner states, one can act in order to overcome them.

At the same time, Mayer considers that each individual has his own way of controlling his emotions, addressing the following emblematic aspects:

- self-awareness: awareness of emotions, when they appear, causes individuals to create an overview of emotional feelings. It is, in fact, about creating a clear image of one's feelings and using intelligence in order to control one's emotions.

- acceptance: it is about accepting one's own dispositions that influence their life, without taking any action to change them. In this context, two directions of manifestation can be identified: there are individuals who easily accept the dispositions they have, people are usually well disposed, so they are not interested in changing their disposition, and those who, although they know very well the states they go through, they are interested in the less pleasant states, states that they accept in a passive way, not taking any action in order to change them.

- closure in one's self: there are individuals who are very often overwhelmed by the emotions that dominate them and cannot get rid of them, somehow they get controlled by them. These individuals get lost among their own feelings, not being very aware of them, failing to look at them in perspective. They often feel overwhelmed because they cannot control their own emotional states. 


\section{EMOTIONAL INTELLIGENCE IN LEADERSHIP}

The fact that emotional intelligence is a key component of effective leadership is unanimously accepted by most authors who have conducted research in this area. George points out that leaders with a high level of emotional intelligence have the ability to recognize, evaluate, and manage emotions in such a way that they can work with people and also motivate their subordinates. (George 2000)

Other authors such as Prati, Douglas, Ferris and Ammeter point out that emotional intelligence is "the indispensable element for effective team interaction but also for increased productivity" and at the same time "team efficiency is determined by the level of emotional intelligence of the team leader." Its role is to motivate the actions of the team and to facilitate the connections between the team members. Also, the truly effective leader "influences the team in a transformative way". (Prati, et al. 2003)

American psychologist Daniel Goleman, an iconic figure in the field of emotional intelligence, found that many of the qualities associated with the leadership phenomenon such as intelligence, toughness, determination, and vision - are necessary for success, but are not enough. To achieve efficiency, truly effective leaders need more than these traits, they must be distinguished by a high degree of emotional intelligence. In this sense, the emotional intelligence of leaders includes selfawareness, self-regulation, motivation, empathy, but also social skills. Listing traits can create a seemingly superficial picture, but Daniel Goleman has identified direct connections between emotional intelligence and business results.

It is true that the relevance of emotional intelligence for business has provoked a lot of debate, Daniel Goleman being the reference author on this topic, describing each component of emotional intelligence, generating detailed discussions on how to recognize potential leaders, how and why to performance and how it can be learned.

It is obvious that, along with emotional intelligence, both cognitive intelligence and technical skills are important, but emotional intelligence is the sine qua non of leadership. Without it, a person can be extremely skilled, analytical, and intelligent, but he cannot meet the conditions to become a true leader.

Within organizations, leaders come first, with multiple responsibilities. In addition to responsibilities related to the smooth running of work tasks, leaders have a major responsibility in terms of the emotional dimension. The leader is, since ancient times, the person who provides all members of the group with security, trust, empathy. Going through many decades in history and reaching the organizations of today, things have not changed a lot. The leader is still the main person responsible for managing the team's emotions, being in fact the one who directs the positive collective emotions in the right direction and eliminates the negative emotions that can have a toxic effect on members of an organization.

How do leaders use their emotional intelligence? How important is emotional intelligence in the leadership context? We have in mind two important questions whose answers have opened the horizon of long discussions.

Success in leadership encompasses three essential elements: self-leadership, leadership of others, but also leadership of the organization.

In terms of self-leadership, successful leaders are aware of their own strengths and weaknesses and are able to continually improve themselves. Awareness of one's own qualities and one's own shortcomings, together with a full self-knowledge of one's own strengths are the first steps in terms of opportunities for development and improvement.

Leaders who do not possess self-knowledge, do not learn from their own mistakes, do not empower their subordinates and do not delegate responsibilities, are leaders who have great chances to fail in the leadership process.

Without awareness of their own strengths and weaknesses, it is virtually impossible for leaders to evolve, to develop new skills, to use their skills constructively. In this context, motivation plays an important role. Setting clear goals, while setting high standards, are the first stones in 
building the road to leadership success. Of course, there are obstacles along this path, but they must be seen as elements that can be overcome, as challenges that will always have a solution.

Self-regulation is also essential in managing all emotions in the leadership process. Very often, leadership means the ability to withstand pressure, to stay calm, to be in control of the situation. Self-leadership encompasses all these elements that any leader must consider.

Regarding the leadership of others, it is obvious that a particularly important role is played by subordinates. In this context, team motivation is one of the important responsibilities of the leader. An effective leader must, in the first instance, be a sufficiently motivated leader who is able to motivate his subordinates as well. The process of motivating subordinates is extremely important, leaders being responsible for developing their motivation. This requires, first, that leaders know the elements that underlie the motivation of subordinates, but also the connection between the motivations of subordinates and the purpose of the organization.

At the same time, leaders must be extremely adaptable and flexible, because team members have different needs, have their own feelings and feelings that often require empathy from the leader.

In this context, social awareness and empathy play an important role in leading teams. Empathy is the core competence of social consciousness that helps leaders connect to people's emotional ensembles. Empathy involves understanding the feelings of employees, but also making decisions that consider the feelings of others. As mentioned above, self-control is an element twinned with empathy, in terms of self-control involves the externalization of emotions in a limited way, in no case inhibiting them.

The last aspect that completes the picture of emotional intelligence in leadership is leadership at the organizational level. The mixture of self-knowledge, self-control and empathy is present in the ultimate ability of emotional intelligence. Managing team members' emotions is closely related to the leader's potential to manage relationships with them. This is possible if leaders become aware of their own emotions and manage to interact empathetically with subordinates.

The main purpose of all leaders' efforts to manage relationships properly, to guide the steps in the right direction, whether it is the question of agreement on a strategy, or openness to daily responsibilities. For this reason, leaders with social skills relate to people from a wide range and can identify commonalities and to build relationships.

The way leaders manage relationships with others, the way they put into practice the art of social interaction, reflects the level of emotional intelligence they possess.

\section{EMOTIONAL INTELLIGENCE IN APPLYING THE COUNSELLOR'S STYLE}

All coordinated activities carried out by the leaders highlight the leadership styles adopted by them. Effective leaders act based on one of the leadership approaches, and depending on the context, use different leadership styles. Leadership styles based on emotional intelligence are visionary style, counsellor, collegiale, democratic, promoter, dominator. (Goleman 2007)

\begin{tabular}{|c|c|c|c|}
\hline No. & $\begin{array}{c}\text { Leadership } \\
\text { style }\end{array}$ & Influence on the climate & Implementation \\
\hline 1. & Visionary & $\begin{array}{c}\text { This leadership style has a necessary influence } \\
\text { on the organizational climate. }\end{array}$ & $\begin{array}{c}\text { It is recommended to be } \\
\text { implemented when a new vision } \\
\text { and a change within the } \\
\text { organization is needed. }\end{array}$ \\
\hline 2. & Counsellor & $\begin{array}{r}\text { This leadership style has a positive influence on } \\
\text { the organizational climate. }\end{array}$ & $\begin{array}{c}\text { It is recommended to be } \\
\text { implemented when followers need } \\
\text { guidance in using their skills. }\end{array}$ \\
\hline 3. & Collegiale & $\begin{array}{r}\text { This leadership style has a positive influence on } \\
\text { the organizational climate. }\end{array}$ & $\begin{array}{c}\text { It is recommended to be } \\
\text { implemted when followers need } \\
\text { motivation, or if they need to } \\
\text { strengthen communication within } \\
\text { the team. }\end{array}$ \\
\hline 4. & Democratic & $\begin{array}{c}\text { This leadership style has a positive influence on } \\
\text { the organizational climate. }\end{array}$ & $\begin{array}{c}\text { Implementation is recommended } \\
\text { when the leader needs the group's } \\
\text { involvement in decision making. }\end{array}$ \\
\hline
\end{tabular}




\begin{tabular}{|c|c|c|c|}
\hline No. & $\begin{array}{c}\text { Leadership } \\
\text { style }\end{array}$ & Influence on the climate & Implementation \\
\hline 5. & Promoter & $\begin{array}{c}\text { If it is not implemented properly, it can have a } \\
\text { negative impact on the organizational climate. }\end{array}$ & $\begin{array}{c}\text { It is recommended to be } \\
\text { implemented if the team members } \\
\text { are competent and if they do not } \\
\text { need many support points. }\end{array}$ \\
\hline 6. & Dominator & $\begin{array}{c}\text { This leadership style can have a negative } \\
\text { impact on the organizational climate if it is used } \\
\text { for a long time. }\end{array}$ & $\begin{array}{c}\text { It is recommended to be used } \\
\text { when it is necessary to implement } \\
\text { a change in the organization. }\end{array}$ \\
\hline
\end{tabular}

How important is emotional intelligence in applying the counsellor's style?

The responsibility of the counsellor leader in terms of subordinates is to support them in identifying their own strengths and weaknesses, while making a connection between them and their own professional and personal aspirations. The counsellor leader is the one who stimulates subordinates to set long-term goals, causing them to outline a plan to achieve them. Usually, when it comes to work, people prefer to select the elements that are related to their aspirations, ideals, and desires. Outlining a close connection between long-term goals and the daily tasks of subordinates is one of the motivational strategies of counsel leaders. However, the implementation of this motivational strategy implies that the leader must know his subordinates very well.

The counsellor leader acts as a trainer, knowing all the goals and qualities of his subordinates, supports them to shape and amplify their skills. The portrait of the counsellor leader focuses on two fundamental traits: self-knowledge and empathy, traits that give that much-needed authenticity to the leader.

Knowing his own emotions and feelings determines the leader to be permanently connected to internal signals, an extremely important element in the leadership context. A leader who possesses a poor self-knowledge, has difficulty in controlling his emotions, in establishing constructive relationships with subordinates. Moreover, empathy plays a key role in the leader-subordinate relationship and in the whole leadership process. Deep self-knowledge helps the leader to transpose into the position of the subordinate, being the initial condition from which empathy emerges.

The counsellor leader knows very well the potential of his subordinates, shows confidence in them and encourages them to do things in the best possible way. Because of these things, people are aware that the leader invests them with confidence and they always feel responsible for what he accomplishes.

\section{CONCLUSIONS}

In today's organizations, one of the essential tasks of leadership is the emotional one that materializes by directing the emotions of all members in a positive direction and eliminating any toxic emotions that may affect their evolution. This task belongs to the leaders, regardless of the level on which they are. If the team's emotions are channelled to exaltation, its members will be able to perform; in the context in which they are treated with indifference, they will no longer yield, the whole organization being affected.

The profile of the contemporary leader has an indispensable component, emotional intelligence, which greatly influences his efficiency in the leadership process. Emotional intelligence is the basic ingredient that provides the skills and abilities necessary to achieve an effective leadership act. All these skills can be developed through appropriate training, through intense efforts aimed at shaping and cultivating them.

A leader at the helm of an organization is even more effective as he has a wide range of skills springing from his emotional intelligence. An empathic leader, with a deep self-knowledge, with a high capacity for self-control, can manage complex leadership situations, can easily imprint change in the organization. Moreover, such a leader uses his emotional skills to direct the organization to change.

Resonant leaders are flexible and constantly adapt to both the situations they face and their subordinates. They do not mechanically correlate leadership styles with situations but are much deeper. They analyse individuals, observing the signs that indicate the leadership style they can 
approach and calibrate them to their needs and characteristics. Therefore, they can apply the six leadership styles, adapted to the nature of the group they must lead.

\section{REFERENCES}

George, Jennifer M. 2000. Emotions and leadership: The role of emotional intelligence. Human Relations.

Goleman, Daniel. 2007. Emotional intelligence in leadership. Bucharest: Curtea Veche.

Mark, Epstein. 1995. Thoughts without a thinker. New York: Basic Books.

Prati, Melita L., Ceasar Douglas, Gerald R. Ferris, Anthony P. Ammeter, and Ronald M. Buckley. 2003. Emotional intelligence, leadership effectiveness, and team outcomes. The International Journal of Organizational Analysis, 21-40.

Day, David. 2014. The Oxford Handbook of Leadership and Organizations, Oxford: Oxford University Press;

Ronald, Heifetz, Marty Linski. 2017. Leadership on the line, Boston, Massachusetts: Harvard Business Review Press;

Warren, Bennis. 2003. On becoming a leader, The leadership classic, revised and updated, Philadelphia: Basic books. 